\title{
Use of platelet gel for the treatment of diabetic foot ulcers
}

\author{
R Russo \\ From de Senectute: Age and Health Forum \\ Catanzaro, Italy. 5-7 December 2009
}

\section{Background}

The aim of this paper is to evaluate the efficacy of platelet gel also for the management of "diabetic foot" lesions. The most important principle considered in this work is the activity of several tissue growth factors inside the pattern of gel.

\section{Materials and methods}

During a period of 4 years, we have considered 42 patients aged between 65 and 75 (F:M 3:1), all submitted to other therapeutic options with failure of previous therapy, Table 1.

The platelet gel is produced from concentrated PLT obtained with different procedures. These derive from the amount of required PTLs, mixed and gelled with Ca-gluconate. The combination with trombin allows the activation of gel. This active gel is immediately put on the lesions.

The following therapeutic scheme is mandatory for the correct practice:

1) antisepsis, cleansing, debridement and monitoring of exudate; 2) application of platelet gel; 3 ) weekly monitoring of lesions, Table 2

\section{Results}

Among the patients presenting stump dehiscence and arterial ulcers healing time has been long (from 4 to 6 months) but satisfactory. The best results have been

Table 1

\begin{tabular}{ll}
\hline Clinical presentation & Nr Cases \\
\hline Stump dehiscence & 8 \\
Arterial ulcers & 14 \\
Neuropathic ulcers & 20 \\
\hline
\end{tabular}

Chair of General Surgery -Vascular Surgery Training Programme - University Magna Graecia of Catanzaro, Italy
Table 2

\begin{tabular}{lll}
\hline $\begin{array}{l}\text { Pathogenesis of } \\
\text { ulcer }\end{array}$ & $\begin{array}{l}\text { Nr Cases treated with } \\
\text { platelet gel }\end{array}$ & $\begin{array}{l}\text { Healing within } \\
\mathbf{1 2} \text { months }\end{array}$ \\
\hline Dehiscence & 8 & 6 \\
Ischemic & 14 & 10 \\
Diabetic & 20 & 14 \\
TOTAL & 42 & 30 \\
\hline
\end{tabular}

observed in patients with neuropathic ulcers, if we consider the healing time of the wound within 6 months from the start of treatment. Of these 20 patients, 14 have presented a complete healing of wounds, 3 undergone a smaller amputation and 3 undergone a bigger amputation, after six months starting treatment.

\section{Conclusions}

The platelet gel may be considered an additional and innovative "weapon" available for the treatment of chronic skin lesions due to ulcers in "non responders" patients to ordinary therapies. It can be clearly considered a useful complement to the most popular and successful alternative therapeutic techniques nowadays in use (advanced dressings, skin grafts, etc.). Another significant feature is related to fast discharge of patients: this represents a very important socioeconomic aspect. The platelet gel dressing is a safe and not expensive technique with rapid healing times; its use should be considered on a large scale.

Published: 19 May 2010

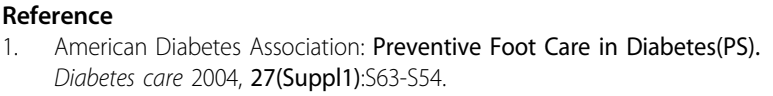

doi:10.1186/1471-2318-10-S1-A76

Cite this article as: Russo: Use of platelet gel for the treatment of diabetic foot ulcers. BMC Geriatrics 2010 10(Suppl 1):A76. 